https://doi.org/10.23913/ride.v10i20.618

Artículos Científicos

\title{
Educación sustentable no formal para conservar los manglares en zonas costeras con estudiantes de Sociología, UAGro
}

Non formal sustainable education to conserve mangroves in coastal areas with students of Sociology, AUGro

Educação sustentável não formal para conservação de manguezais em áreas costeiras com estudantes de Sociologia, UAGro

Adriana Miranda Esteban

Universidad Autónoma de Guerrero, México

mar86_05@hotmail.com https://orcid.org/0000-0003-4313-6146

*Ramón Bedolla Solano

Universidad Autónoma de Guerrero, México

rabedsol@hotmail.com

https://orcid.org/0000-0001-6219-4953

*Juan José Bedolla Solano

Tecnológico Nacional de México, ITA Acapulco, México jjosebedolla@hotmail.com

https://orcid.org/0000-0001-6999-8823

Oscar Sánchez Adame Universidad Autónoma de Guerrero, México msposcar@hotmail.com https://orcid.org/0000-0001-5202-3835

*Autores de correspondencia 


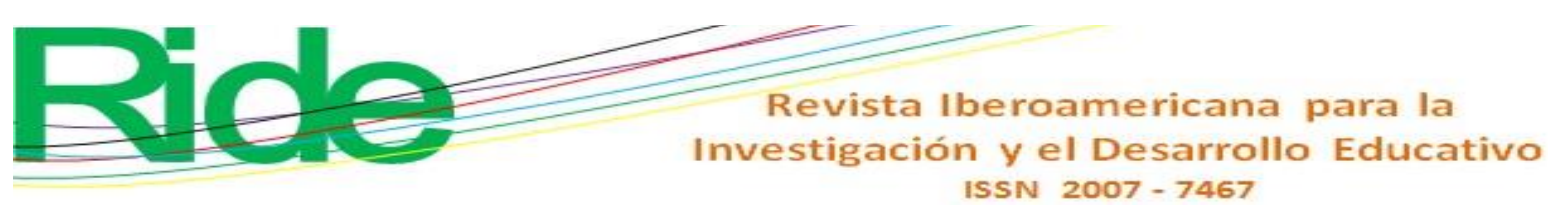

deben incorporar el principio de transversalidad curricular en la enseñanza de la Educación Ambiental para el desarrollo sostenible a través de sus sistemas educativos. Linares, Tovilla y De la Preza (2004a) consideran que la Educación Ambiental es necesaria para ayudar a crear conciencia sobre el problema que afecta a los manglares en la actualidad. También establecen que, a través de talleres para la protección de los manglares, se ha logrado involucrar a algunas personas sobre el aprovechamiento del manglar y sus recursos.

Palabras clave: educación ambiental no formal, manglares, socioambiental, sustentabilidad.

\section{Abstract}

Faced with the environmental crisis, the importance of education arises. Universities have the commitment to contribute to sustainability, it is necessary that the environmental dimension is included in the curriculum, so that this dimension implies developing environmental issues in a transversal way, or activities that contribute to understanding the socio-environmental reality for students to analyze the environmental crisis and intervene with strategies, however, sometimes, the curricula are not environmentalized or do not integrate cross-cutting issues such as the environment, and it is necessary to go to non-formal Environmental Education (EE) for this reason, non-formal intervention educational programs are designed and thus contribute to the sustainability that is required. The research was carried out in January-September 2019 and its purpose was to make a diagnosis to identify the presence of the environmental dimension in the Study Plan of the Higher School of Sociology (SPHSS) under the Autonomous University of Guerrero (AUGro) and Implement and evaluate a non-formal workshop-course on Environmental Education aimed at the conservation of mangroves with a socio-environmental approach for students of that institution. The Educational Model of the UAGro establishes sustainability as a guiding principle, however, the (SPHSS) contemplates very little to the environment or said principle.

It was a mixed study, with a focus on action research and descriptive, contemplated three phases, a diagnosis to identify the environmental dimension in the curriculum, therefore, an interview was conducted with students, with variables (inclusion of the environmental dimension in the SPHSS, perception of the environmental crisis, importance of EE and the mangroves), the second phase included the design and elaboration with their respective didactic planning of the course-workshop, a constructivist and competency methodology was followed, the themes that were defined were Environmental Education and the conservation of mangroves, the third included the application and evaluation of the course-workshop in question. 


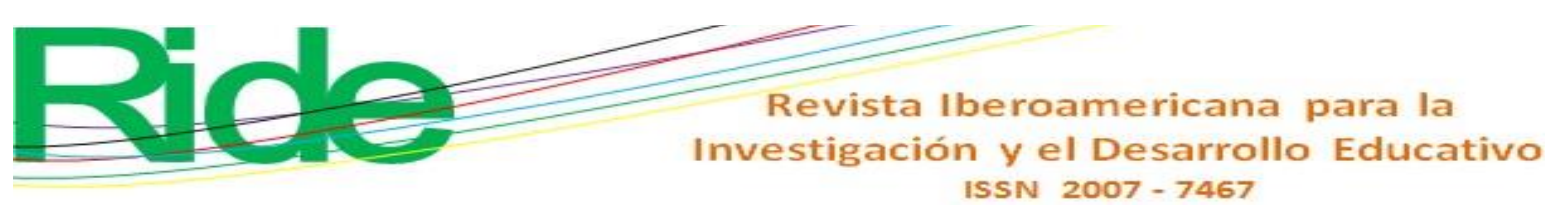

da Universidade Autônoma de Guerrero (UAGro) e Implementar e avaliar um curso não formal de educação ambiental voltado para a conservação de manguezais, com uma abordagem socioambiental para os alunos daquela instituição. O Modelo Educacional da UAGro estabelece a sustentabilidade como princípio norteador, no entanto, o (PEESS) contempla muito pouco o meio ambiente ou o referido princípio.

Foi um estudo misto, com foco em pesquisa-ação e descritivo, contemplado três fases, um diagnóstico para identificar a dimensão ambiental no currículo, portanto, foi realizada uma entrevista com os alunos, com variáveis (inclusão da dimensão ambiental no currículo). (PEESS, percepção da crise ambiental, importância da EA e manguezais), a segunda fase incluiu o desenho e a elaboração do respectivo planejamento didático do curso-workshop, seguiu-se uma metodologia construtivista e de competência, os temas definidos foram Educação Ambiental e conservação de manguezais, a terceira incluiu a aplicação e avaliação do workshop-curso em questão.

Os resultados indicaram que o PEESS mal integra a dimensão ambiental, porque as unidades de aprendizagem que o conformam não vinculam o tema ambiental aos seus objetivos, os professores não possuem competências nesse campo, os alunos não promovem competências ambientais entre outros . Na segunda fase, foi possível preparar um curso de oficina sobre Educação Ambiental para conservar manguezais com base científica, contemplou duas sessões, atividades e métodos de avaliação e na terceira fase, "aplicação e avaliação" foram assistidas por setenta alunos das diferentes séries que participaram do treinamento, a avaliação realizada permitiu saber que o aprendizado e as habilidades foram adquiridos na EA e proteger e conservar os manguezais.

O Modelo Educacional da UAGro estabelece sustentabilidade e, portanto, a introdução de questões transversais como meio ambiente e outros temas, mas o PEESS mal contempla essa dimensão. Autores como Yanes e Álvarez (2019) afirmam que diferentes países devem incorporar o princípio da integração curricular no ensino da educação ambiental para o desenvolvimento sustentável por meio de seus sistemas educacionais. Linares, Tovilla e De la Presa (2004a) consideraram que a educação ambiental é necessária para ajudar a aumentar a conscientização sobre o problema que afeta hoje as florestas de mangue, eles também comentam que, através de oficinas para a proteção de manguezais, tem sido conseguiu envolver algumas pessoas para um uso racional do homem e de seus recursos. 


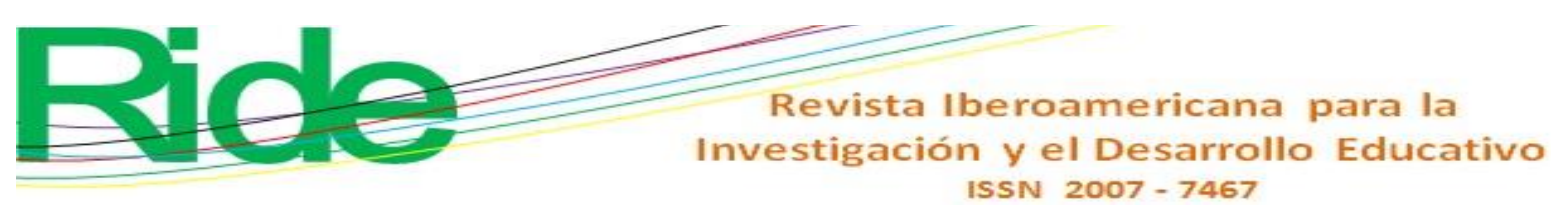

Palavras-chave: Educação Ambiental Não Formal, sustentabilidade, manguezais, socioambientais.

Fecha Recepción: Octubre 2019

Fecha Aceptación: Febrero 2020

\section{Introducción}

El trabajo que ahora se presenta tiene como antecedente el modelo educativo de la Universidad Autónoma de Guerrero, el cual se enfoca en la sustentabilidad como uno de los principios fundamentales para fomentar la educación de calidad. Este hace énfasis en las problemáticas ambientales con un enfoque socioambiental, esto a raíz de la crisis climática que se presenta en todo el planeta. En tal sentido, se ha determinado que los planes de estudio de los niveles educativos que se imparten en la referida institución deben integrar temas emergentes como la pobreza, la perspectiva de género, el medio ambiente, entre otros, a través de un método transversal. Dicho esto, la presente investigación se justifica porque con esta se intenta conocer la integración de la dimensión ambiental en los planes de estudio.

Como se sabe, la problemática ambiental va en aumento, en especial en lo referido a la biodiversidad. Los manglares, por ejemplo, son plantas que por lo general nacen en zonas costeras y proporcionan suficientes beneficios; sin embargo, las personas están interviniendo en su deterioro, de modo que es necesario que se divulguen conocimientos, habilidades y valores para su protección y conservación.

La conservación de nuestros ecosistemas costeros requiere que los estudiantes, los habitantes de esas zonas y el público en general tengan mayor información sobre ellos. Hoy en día, ante los escenarios de cambio climático y los desastres que han afectado a los pobladores costeros, esta exigencia se hace aún más relevante. El sensibilizar a la población permitirá que haya mayor contacto entre los ciudadanos y la naturaleza (Moreno-Casasola e Infante, 2016).

Los manglares en México se distribuyen en el interior de lagunas costeras y sistemas deltaicos de las costas del golfo de México y del océano Pacífico, con algunas lagunas costeras que poseen bocas efímeras que se abren durante la temporada de lluvias o por acción de los pescadores (López y Escurra, 2002).

México es un país privilegiado por su biodiversidad, de ahí que ocupe los primeros lugares en todas las listas referidas a este aspecto. La biodiversidad, según Díaz (2011), abarca tres niveles de expresión de variabilidad biológica: ecosistemas, especies y genes. Para el citado autor (2011) 


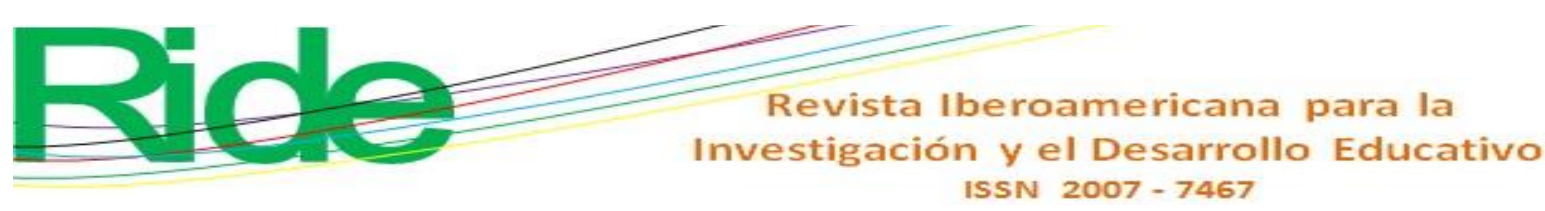

los manglares —regionalmente conocidos como mangles - se ubican en el ecosistema constituido por árboles o arbustos que crecen en las zonas costeras de regiones tropicales y subtropicales. Los manglares son los denominados bosques de mangle, presentes en las regiones tropicales y subtropicales del mundo (Wolanski, citado por Mera, 1999). Son un grupo de halófitos altamente evolucionados que crecen en la franja localizada en la frontera entre las aguas marinas y la tierra firme, generalmente en la zona entre mareas de estuarios, lagunas y pantanos costaneros, de ahí que frecuentemente se inundan de agua de mar durante las mareas altas (Gang y Agatsiva citados por Mera, 1999).

Los manglares mexicanos son ecosistemas estructuralmente heterogéneos debido a la amplia gama de características ambientales de los lugares donde se desarrollan, resultado de la combinación de factores climáticos, biofísicos, geomorfológicos, hidrológicos y biológicos (Rodríguez et al., 2018). Según González (18 de mayo de 2018), del manglar se extrae la palabra mangle. Un manglar es un bioma que también es llamado bosque salado o humedal costero, el cual se halla en las zonas tropicales y subtropicales, en especial en suelos pantanosos y anegados. Actualmente, se pueden numerar una diversidad de manglares, según el tipo de árbol que en ellos crece o la zona en que se ubiquen.

Por ejemplo, en el primer caso, existe el mangle blanco, el rojo, el negro y el gris (aunque en realidad existen unas 70 especies arbóreas de esta familia). Igualmente, por la ubicación del manglar se puede determinar una tipología diferente. En este caso, son ribereños cuando están a las orillas de ríos o en partes en que hay influencia de las mareas. Son bordes cuando están protegidos por bahías o lagunas. Se consideran cuencas si están en suelos estables con renovación lenta de agua. Y son especiales cuando son pequeños y evolucionan en ambientes de alta salinidad y pocos nutrientes, desarrollando temperaturas extremas.

Para López et al. (citados por Valderrama et al., 2017), los manglares son un tipo de vegetación característica de las zonas costeras de los trópicos y subtrópicos de todo el mundo. En México se encuentran presentes en ambos litorales (Atlántico y Pacífico), cubriendo al menos $60 \%$ de la línea costera nacional. En el país existen seis especies, cuatro de las cuales son comunes: el mangle rojo (Rhizophora mangle), el mangle blanco (Laguncularia racemosa), el mangle negro (Avicennia germinans) y el mangle botoncillo (Conocarpus erectus y Conocarpus erecutus var. sericeus). Dos de estas especies (Avicennia bicolor y Rhizophora harrisonii), en cambio, tienen una distribución muy restringida, con presencia de solo algunas poblaciones aisladas en los estados de Chiapas y Oaxaca. 


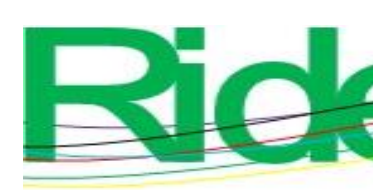

Revista Iberoamericana para la Investigación y el Desarrollo Educativo

ISSN $2007-7467$

De acuerdo con la Organización de las Naciones Unidas para la Alimentación y la Agricultura (FAO) (citada por Valderrama et al., 2017), este ecosistema es especialmente importante, ya que provee beneficios ambientales ampliamente conocidos, como el control de inundaciones, protección contra huracanes, fuente de nutrientes para ecosistemas vecinos como arrecifes de coral y captura de gases de efecto invernadero, entre muchos otros. A lo largo de las últimas dos décadas, la importancia de la conservación y protección de los manglares se incrementó de manera sustancial a nivel mundial y nacional. Según la información de la Secretaría de Medio Ambiente y Recursos Naturales (Semarnat) (2016), México ocupa el cuarto lugar mundial en extensión de humedales costeros después de Indonesia, Brasil y Australia.

Los manglares proporcionan importantes servicios ambientales, como protección y regulación de inundaciones, recarga de los acuíferos, mejora de la calidad del agua al servir como filtro biológico, prevención y reducción de la erosión costera, regulación de la calidad del agua y la captación de carbono. En otras palabras, constituyen zonas de alimentación, refugio y crecimiento de crustáceos, alevines y otras especies de flora y fauna.

En los bosques de manglar de las costas mexicanas se encuentran cinco especies de mangles, de las cuales presentan mayor abundancia Rhizophora mangle L. (mangle rojo), Avicennia germinans L. (mangle negro o mangle prieto), Laguncularia racemosa (L.) Gaertn (mangle blanco) y Conocarpus erectus L. (mangle botoncillo). Asimismo, últimamente, Rhizophora harrisonnii Leechman en el estado de Chiapas (Rico-Gray et al., citados por Aguirre, 2018).

\section{La problemática ambiental}

En la actualidad se repite hasta el cansancio que la crisis ambiental global, con sus distintas variables (como el cambio climático y la pérdida de la biodiversidad, entre otras), es la "mayor amenaza" que ha afectado a la humanidad en toda su historia (Estenssoro, 2018). Según Garrido et al. (2007) citado en Ramírez (2015), esta crisis se expresa en eventos concretos, como el efecto invernadero, el agujero de la capa de ozono, el vaciado de los combustibles fósiles, la deforestación, la sobreexplotación y el agotamiento de los recursos hídricos, la contaminación atmosférica, la lluvia ácida, la erosión, entre otros fenómenos. En otras palabras, la biodiversidad se encuentra amenazada por varios procesos (la mayoría antropogénicos, que transforman el entorno en el que vivimos). Entre ellos se pueden citar los siguientes: 1) las especies invasoras y 2) la pérdida y fragmentación de los hábitats. Esta última es considerada la causa primaria de la pérdida de la 


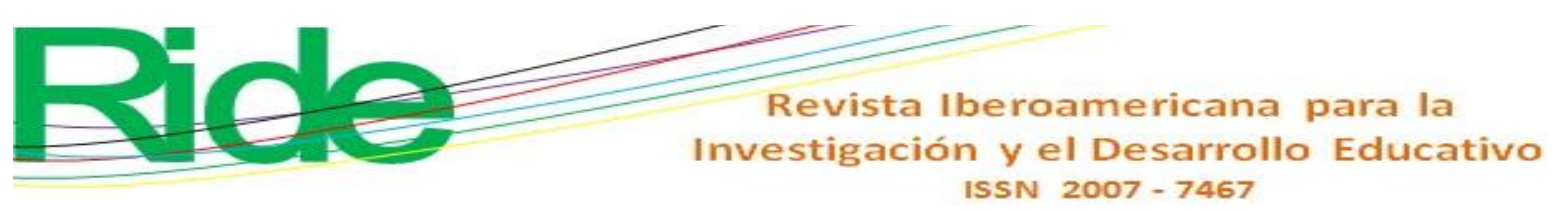

biodiversidad en todos los niveles, y surge principalmente por los cambios en el uso del suelo para la agricultura, la ganadería, la acuacultura, etc., fenómeno causado por la expansión de las poblaciones y las actividades humanas (Plascencia, Castañón y Raz-Guzmán, 2011).

Los problemas ambientales son impulsados por fuerzas motrices como los cambios de uso de suelo (ganadería, cultivos ilícitos e infraestructura), la disminución, la pérdida y la degradación de elementos en los ecosistemas nativos y agroecosistemas (agroindustria, minería, hidroeléctricas, urbanización y sobreexplotación de peces), la contaminación del agua (minería y uso de plaguicidas) y el cambio climático (MADS y PNUD citados por Ramírez, 2015).

En los últimos 50 años, los manglares del mundo se han reducido a la mitad. Estos ecosistemas costeros tienen la capacidad de almacenar más carbono que muchos bosques tropicales. Aun así, están siendo destruidos de las costas rápidamente, emitiendo enormes cantidades de gases de efecto invernadero (Heredero, 15 de abril de 2011). Los bosques de manglar son ecosistemas muy complejos con múltiples funciones ecológicas y alto valor económico. Son también ecosistemas que están sujetos a diversos impactos negativos, lo que está ocasionando su desaparición a una tasa anual que oscila entre 1 \% y 5 \% (Olguín, Hernández y Sánchez, 2007).

Greenpeace (2009) señala que en nuestro país la superficie de manglar está desapareciendo a un ritmo de $2.5 \%$ anual, mientras que, a nivel global, la FAO reporta un índice de pérdida de este ecosistema de $0.66 \%$. Alejandro Olivera, coordinador de campañas de Greenpeace México, manifestó en nota publicada en el 2019 en la página de Greenpeace que "Es necesario impedir que se sigan destruyendo manglares a cambio de compensaciones económicas e impedir la construcción de centros turísticos no sustentables y que solo dejan beneficios en el corto plazo y a un grupo social no restringido. Hacemos un llamado a los legisladores y al gobierno federal a proteger a este ecosistema costero y los beneficios que representa. Basta de autorizaciones ilegales". Así como sucede con la agricultura basada en la tierra, la acuicultura y las actividades económicas han ocasionado problemas ambientales y conflictos sociales de gran relevancia en las zonas costeras.

Se han presentado modificaciones de los hábitats en los lugares donde los acuicultores eliminan los manglares para establecer piscinas para la cría de especies de importancia económica (como camarones, langostinos y peces), donde se instalan jaulas o corrales por encima de pastos marinos y arrecifes coralinos. Algunos efectos ambientales asociados a esta problemática son la pérdida de peces e invertebrados que se descartan de las redes por ser indeseados, la introducción de especies exóticas, el esparcimiento de parásitos y enfermedades, el uso inadecuado de químicos, 


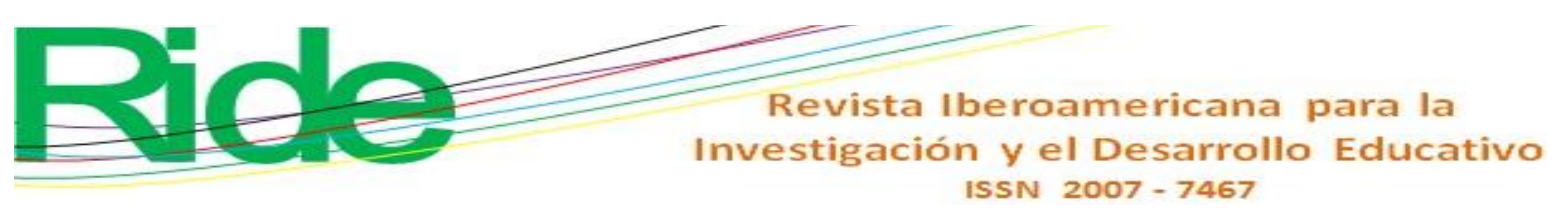

la salinización del suelo y del agua, y la contaminación de las zonas costeras (FAO citada por Uribe y Urrego, 2009).

Arroyo, Camarero y Vásquez (citados por Yépez, 2018) señalan que "el hombre sin dejar de ser un elemento del medio natural se va transformando en un factor del mismo del que depende el funcionamiento de la mayoría de los ecosistemas e incluso su conservación" (p. 89). Por ende, el vivir y disfrutar de un entorno natural convierte al vecino que lo ve día a día en un ente ecológico, de ahí que deba conservar este entorno. Álvarez y Vega (citados por Yépez, 2018), y refiriéndose a los individuos, explican que estos únicamente desarrollan conductas ambientalmente consecuentes si están capacitados "sobre la problemática ambiental, se encuentran motivados hacia ella y, además, se ven capaces de generar cambios cualitativos, están convencidos de la efectividad de su acción y de que esta no le generará dificultades importantes, si se asume que la capacitación a la que se refiere el autor es adquirir conocimientos" (p. 89).

\section{Desarrollo sostenible}

El desarrollo sostenible implica una nueva visión del mundo y de relacionar a la naturaleza, lo que implica transformaciones en diferentes áreas, como la científica, tecnológica, social, política, económica, cultural y educativa (Calixto, 2018). Por eso, "el modelo para la formación ambiental debe basarse en principios de sostenibilidad y para ello, es necesario comprender las conexiones entre los problemas económicos, políticos y los conflictos socioambientales" (Vega citado por Molano y Herrera, 2014, p. 192). En otras palabras, la educación es una herramienta importante para coadyuvar en el desarrollo sostenible.

\section{Educación ambiental para la sustentabilidad}

Por educación se entiende un proceso de desarrollo sociocultural continuo de las capacidades que las personas en sociedad deben generar, lo cual se realiza tanto dentro como fuera de su entorno a lo largo de toda la vida. La educación implica impulsar las destrezas y las estructuras cognitivas que permiten que los estímulos sensoriales y la percepción del mundorealidad se conviertan de información significativa en conocimientos de su construcción y reconstrucción, así como en valores y costumbres que determinan nuestros comportamientos (Álvarez citado por Martínez Castillo, 2010). La crisis ambiental ha llegado a un nivel tan alarmante que ahora se debe, por medio de la educación, crear conciencia de la importancia de cambiar las formas de producción y bienestar social, así como del respeto a la diversidad cultural 


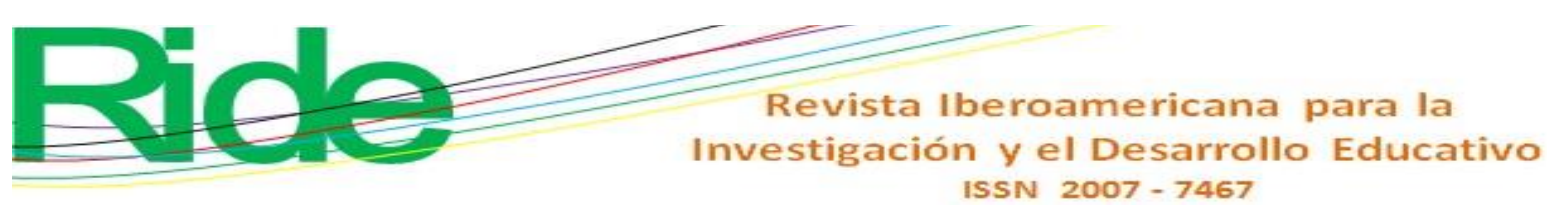

y a las condiciones que posibilitan la existencia de la vida en el planeta. En este contexto se hace evidente lo significativo de la educación ambiental como una de las alternativas para el reconocimiento del valor de la conservación de las condiciones naturales del planeta (Calixto, 2015). En la actualidad se habla de educación ambiental como el medio más efectivo para concienciar a la población sobre la necesidad de preservar el ambiente con miras a lograr una mejor calidad de vida de las generaciones actuales y por venir.

Ahora bien, el concepto educación ambiental se usó por primera vez en Estocolmo (Suecia) en 1972 durante la Conferencia Internacional sobre el Medio Ambiente, y desde entonces se le ha concedido la preponderancia para generar los cambios mediante la adquisición de conocimientos, actitudes y valores que permitan enfrentar seriamente la crisis ambiental del mundo (SerevicheSierra, Gómez-Bustamante y Jaimes-Morales, 2016).

Luego, a finales de la década de los ochenta y la primera mitad de los noventa el término educación ambiental no solo se empezó a vincular con el de desarrollo sostenible, sino que también se definió de la siguiente manera:

Proceso de aprendizaje permanente, basado en el respeto a todas las formas de vida (...). Tal educación afirma valores y acciones que contribuyen a la transformación humana y social y a la preservación ecológica. Ella estimula la formación de sociedades socialmente justas y ecológicamente equilibradas, que conserven entre sí una relación de interdependencia y diversidad (González, 1996, p.27).

La educación ambiental, por ende, debe enseñar cómo se puede continuar con el desarrollo mientras se protegen y se conservan los sistemas de soporte vital del planeta, y en tal sentido la cultura para la conservación y rehabilitación de los bosques de manglar requiere de una mayor atención. La educación, en efecto, es un agente fortalecedor integral que promueve el conocimiento de los problemas del medio natural y social y los vincula sólidamente con sus causas. A través de la educación se puede enseñar a los habitantes a aprovechar racionalmente el ecosistema (Linares, Tovilla y De la Presa, 2004). La educación ambiental, en pocas palabras, es esencial para ayudar a la concientización sobre la problemática que enfrentan los bosques de manglares en la actualidad (Linares, Tovilla y De la Presa, 2004). 


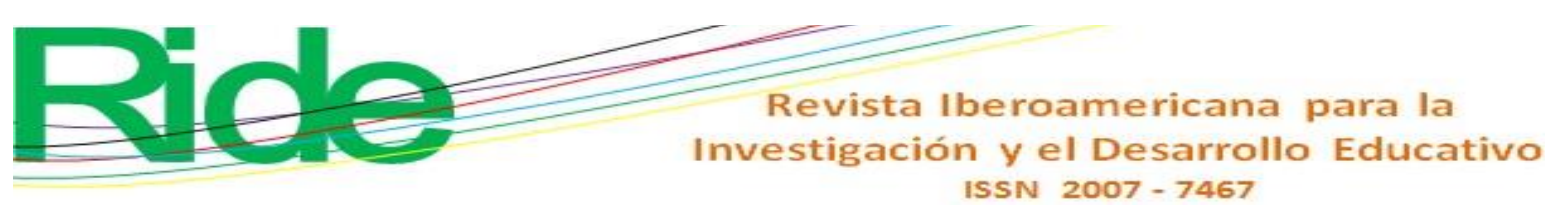

Población y muestra

En la tabla 1 se describen la población y la muestra consideradas en este proceso de investigación:

Tabla 1. Población y muestra seleccionadas

\begin{tabular}{|c|c|c|c|c|c|c|}
\hline \multicolumn{2}{|c|}{$\begin{array}{c}\text { Población general en } \\
\text { la Universidad } \\
\text { Autónoma de } \\
\text { Guerrero }\end{array}$} & $\begin{array}{l}\text { Univers } \\
\text { o de } \\
\text { estudio }\end{array}$ & $\begin{array}{c}\text { Población de } \\
\text { la Escuela de } \\
\text { Sociología }\end{array}$ & $\begin{array}{c}\text { Muestra } \\
\text { (participantes } \\
\text { en el } \\
\text { diagnóstico, } \\
\text { previo al } \\
\text { curso-taller) }\end{array}$ & $\begin{array}{c}\text { Muestra } \\
\text { (participantes en } \\
\text { el curso-taller de } \\
\text { educación } \\
\text { ambiental para la } \\
\text { conservación de } \\
\text { manglares) }\end{array}$ & $\begin{array}{c}\text { Enfoque de } \\
\text { selección de la } \\
\text { muestra y edad } \\
\text { de los } \\
\text { participantes }\end{array}$ \\
\hline $\begin{array}{l}\text { Universida } \\
\text { d } \\
\text { Autónoma } \\
\text { de } \\
\text { Guerrero, } \\
\text { México }\end{array}$ & $\begin{array}{l}* \text { Profeso } \\
\text { res } \\
(1162) \\
383 \\
\text { mujeres } \\
779 \\
\text { hombres }\end{array}$ & $\begin{array}{l}\text { Escuela } \\
\text { de } \\
\text { Sociolo } \\
\text { gía }\end{array}$ & $\begin{array}{l}\text { **17 (15 } \\
\text { hombres, } 2 \\
\text { mujeres) } \\
\text { profesores y } \\
238 \text { (96 } \\
\text { hombres-142 } \\
\text { mujeres) } \\
\text { estudiantes de } \\
\text { sociología }\end{array}$ & $\begin{array}{l}115 \\
\text { estudiantes de } \\
\text { los grupos, } \\
201,202, \\
401,402,601, \\
602 \text { (turnos: } \\
\text { matutino y } \\
\text { vespertino) }\end{array}$ & $\begin{array}{l}70 \text { estudiantes de } \\
\text { los grupos } 201, \\
401,601 \text { y } 801 \\
\text { del turno } \\
\text { matutino } \\
\text { asistieron al } \\
\text { primer y segundo } \\
\text { taller }\end{array}$ & $\begin{array}{l}\text { Cualitativo y } \\
\text { por } \\
\text { conveniencia. } \\
\text { La edad de los } \\
\text { estudiantes } \\
\text { oscila entre } \\
18-23 \text { años }\end{array}$ \\
\hline
\end{tabular}

Fuente: Elaboración propia con datos del *Anuario Estadístico 2013-2014, 2014-2015 y **20162017 de la Universidad Autónoma de Guerrero

\section{Técnicas, procedimiento e instrumentos empleados}

La investigación se desarrolló en tres fases:

\section{Fase a: Diagnóstico para identificar la inclusión de temáticas ambientales con enfoque sustentable en el plan de estudio}

Se realizó un diagnóstico con estudiantes de sociología para identificar la inclusión de la dimensión ambiental y la sustentabilidad en el plan de estudios de sociología, así como la percepción de la problemática ambiental y el cuidado de la biodiversidad y los manglares. Se realizó una entrevista con variables e indicadores (inclusión de la dimensión ambiental y sustentabilidad en el plan de estudio, percepción de la crisis ambiental, importancia de la educación 


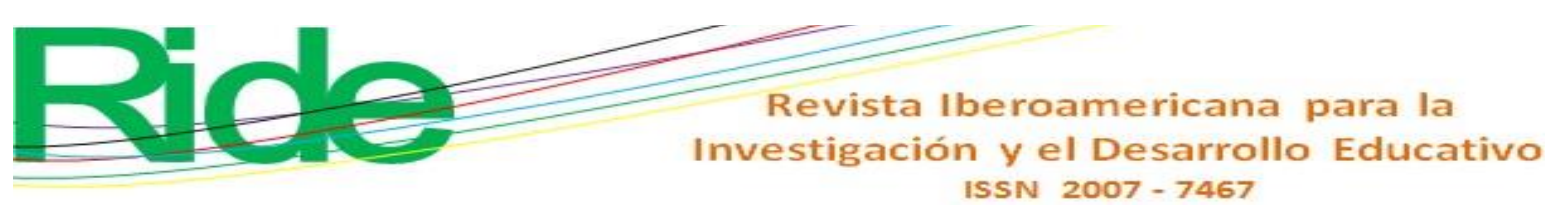

ambiental para la biodiversidad y los manglares) aplicada a 115 estudiantes, incluidos hombres y mujeres de diferentes grados académicos.

\section{Fase b: Diseño pedagógico-didáctico del curso-taller}

Se diseñó la secuencia didáctica que estableció la planeación sobre el conjunto de estrategias educativas, actividades didácticas y métodos de evaluación de aprendizajes para el curso-taller Educación ambiental para la conservación de manglares.

\section{Fase c: Aplicación y evaluación del curso-taller.}

Se aplicó y evaluó el curso-taller Educación ambiental para la conservación de manglares. Durante este se realizaron evaluaciones diagnósticas, continuas y finales para detectar los aprendizajes y competencias adquiridas.

\section{Resultados}

\section{Fase a: Diagnóstico para identificar la inclusión de temáticas ambientales con enfoque sustentable en el plan de estudio}

Considerando el enfoque de selección de la muestra (cualitativo y por conveniencia), se eligió para la aplicación de la entrevista a 115 estudiantes entre hombres y mujeres. En tal sentido, vale acotar que la escuela cuenta con dos grupos por grado: uno en la mañana y otro en la tarde (en cada semestre del año). La encuesta fue contestada por 22 estudiantes del grupo 201 (turno matutino), 13 del grupo 202 (turno vespertino), 14 del grupo 401 (turno matutino), 13 del grupo 402 (turno vespertino), 18 del grupo 601 (turno matutino), 10 del grupo 602 (turno vespertino), 10 del grupo 801 (turno matutino) y 15 del grupo 802 (turno vespertino).

El objetivo de la entrevista consistió en identificar la inclusión de la dimensión ambiental en el plan de estudios de sociología para determinar la percepción que se tiene de la problemática ambiental (específicamente del cuidado de la biodiversidad y los manglares). En total, se formularon 17 preguntas, las cuales se agruparon en las siguientes categorías: inclusión de la dimensión ambiental y sustentabilidad en el plan de estudio, percepción de la crisis ambiental e importancia de la educación ambiental para la biodiversidad y los manglares. 


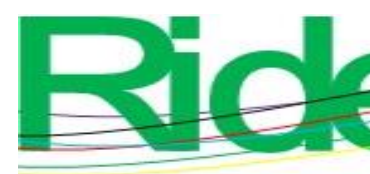

\section{Revista Iberoamericana para la Investigación y el Desarrollo Educativo ISSN $2007-7467$}

\section{Inclusión de la dimensión ambiental y sustentabilidad en el plan de estudio}

Todos los entrevistados manifestaron que no sabían a qué se referían los conceptos desarrollo sustentable o sustentabilidad. Específicamente, $5 \%$ relacionan su respuesta con el medio ambiente o con cuidar el medio y los recursos, aunque también vale destacar que en otros casos se refirieron a aspectos que no tienen relación con los referidos conceptos. Asimismo, $10 \%$ de los encuestados relacionan estos términos con desarrollo, medio ambiente y cuestiones sociales.

En relación con la incorporación de la dimensión ambiental o medio ambiente en el plan de estudio, más de 100 entrevistados comentaron que no se incorpora; además, $5 \%$ comentó que se podría integrar dicha dimensión al currículo a través de conferencias o presentaciones vinculadas con temáticas del medio ambiente. Cuando se preguntó si las materias cursadas se relacionaban con la dimensión ambiental, $98 \%$ contestó de forma negativa, mientras que solo $3 \%$ dijo que eso sucedía únicamente en algunas oportunidades.

\section{Percepción de la crisis ambiental}

Ante la pregunta ¿Explica cómo las problemáticas ambientales afectan al desarrollo social $y$, por ende, sustentable?, todos los encuestados desconocían que cuando se afectaba el medio se producía un estancamiento en el desarrollo de todos sus ámbitos. De hecho, solo $10 \%$ percibió que las problemáticas ambientales eran un asunto que se debía atender con urgencia, mientras que otro $10 \%$ relacionó la contaminación existente con diversas afectaciones a la salud. En definitiva, 98 \% manifestó que las unidades de aprendizajes o materias no se vinculaban con la crisis ambiental.

\section{Importancia de la educación ambiental para la biodiversidad y los manglares}

Los 115 estudiantes consultados opinaron que era muy importante cuidar y preservar las plantas y los animales debido al peligro de extinción al que estaban expuestos, aunque en relación con los manglares manifestaron que no conocían mucho al respecto.

Asimismo, y ante otras preguntas (p. ej., ¿consideras que es importante promover competencias de Educación Ambiental? y ¿consideras que es importante tomar cursos-talleres que aborden las temáticas de medio ambiente como la conservación de los manglares?), los 115 estudiantes contestaron afirmativamente, pues consideraron, además, que la carrera que cursaban no tocaban esas temáticas. Aunado a esto, todos opinaron que la dimensión ambiental debe estar presente en el currículo escolar para contar con competencias que permitan encarar y atender esa problemática ambiental que podría afectar el desarrollo social. 


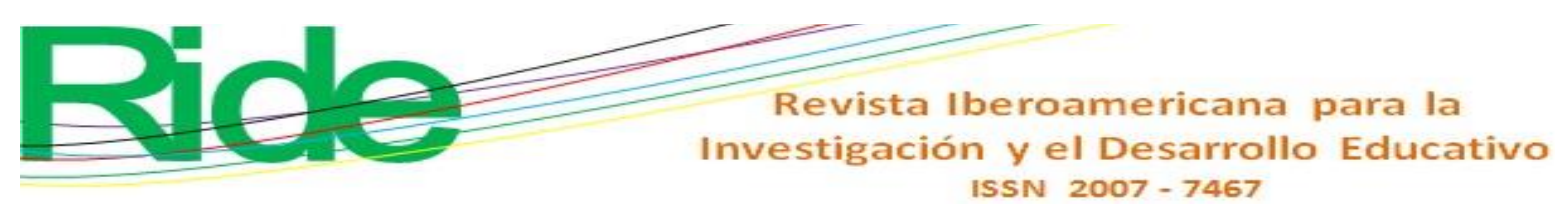

\section{Fase b: Diseño pedagógico-didáctico del curso-taller}

Nieto y Buendía (2008) establecen que una de las fases del diseño de un proyecto de educación ambiental para la sustentabilidad es la contextualización; esta consiste en caracterizar la red de relaciones más significativas que hay entre el entorno del proyecto donde se espera tener una cierta contribución e impacto y los elementos básicos del proyecto educativo (es decir, contenidos, objetivos, actividades, etc.).

Una vez concretada la contextualización, se procede a la planeación de actividades específicas (secuencia didáctica). El diseño y elaboración de una secuencia didáctica implica adoptar un enfoque didáctico-pedagógico y metodológico para planear el desarrollo de las temáticas que competen al curso o taller, así como de las estrategias, formas de evaluación, etc. En el Oxford Dictionaries (2019) se define la palabra diseñar como un plan detallado para la ejecución de una acción o una idea. Asimismo, el vocablo diseño se plantea como una actividad creativa que tiene por fin proyectar objetos que sean útiles.

Planificar, por tanto, se asocia con una guía racional y estructurada en la que se toma en cuenta qué se quiere conseguir, qué se pretende transmitir, cómo se va a hacer, cómo se puede reaccionar en caso de que surja algún imprevisto, qué recursos se necesitan y cómo se puede evaluar la actividad (Ruiz, s. f.).

Ahora bien, el sustento teórico de esta secuencia didáctica se halla en la obra de Tobón, Pimienta y García (2010), quienes ofrecen una metodología estándar general para planificar actividades por competencias desde un enfoque socioformativo. El formato empleado fue una adaptación del usado en la Universidad Autónoma de Guerrero en planeaciones didácticas de nivel licenciatura.

El curso-taller se apoyó en los principios del constructivismo y la educación por competencias. El constructivismo postula que el conocimiento se adquiere cuando una persona construye significados interactuando de forma intencional con otras personas. Las competencias construyen en las y los estudiantes el mejor desempeño para responder a las demandas del entorno (Cuevas, Rocha, Casco y Martínez, 2011). En la tabla 2 se describe la estrategia educativa implementada en las dos sesiones del curso-taller.

Tabla 2. Estrategia educativa de la sesión 1 y 2 del curso-taller, Educación Ambiental para la conservación de manglares: 


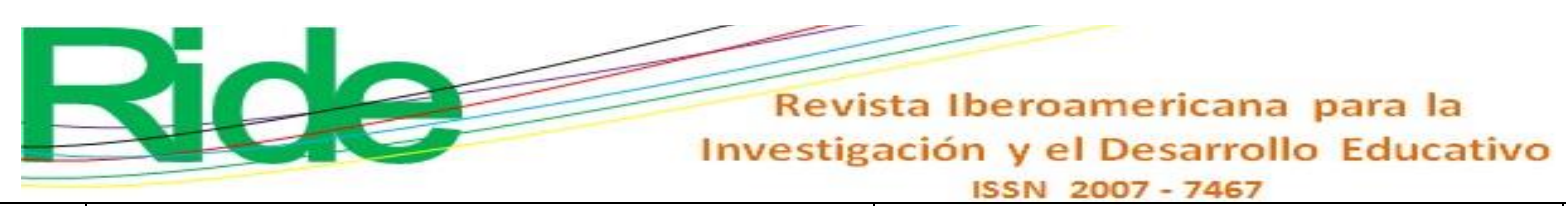

\begin{tabular}{|c|c|c|c|c|c|c|}
\hline \multirow{2}{*}{$\begin{array}{c}\text { Sesión } \\
\text { Fecha } \\
\text { Eje } \\
\text { integrador }\end{array}$} & \multicolumn{2}{|c|}{ Actividades de aprendizaje } & \multicolumn{3}{|c|}{ Evaluación } & \multirow{2}{*}{$\begin{array}{c}\text { Recurs } \\
\text { os de } \\
\text { aprend } \\
\text { izaje } \\
\end{array}$} \\
\hline & $\begin{array}{c}\text { Actividades con el docente } \\
\text { (tiempo) }\end{array}$ & $\begin{array}{c}\text { Activida } \\
\text { des de } \\
\text { aprendiz } \\
\text { aje } \\
\text { indepen } \\
\text { diente } \\
\end{array}$ & $\begin{array}{c}\text { Criterios } \\
\text { (aprendiz } \\
\text { ajes } \\
\text { esperados } \\
\text { ) }\end{array}$ & Evidencias & $\begin{array}{c}\text { Pond } \\
\text { eració } \\
n\end{array}$ & \\
\hline $\begin{array}{l}\text { Sesión } 1 \\
\text { (28 de mayo } \\
\text { de 2019) } \\
\text { Educación } \\
\text { ambiental } \\
\text { para la } \\
\text { sustentabili } \\
\text { dad }\end{array}$ & $\begin{array}{l}\text { Técnica: Lluvia de ideas } \\
\text { El facilitador pide a los } \\
\text { estudiantes que mencionen las } \\
\text { problemáticas ambientales que } \\
\text { conozcan. } \\
\text { Tiempo: } 15 \text { minutos } \\
\text { El facilitador pregunta qué } \\
\text { entienden por educación } \\
\text { ambiental. } \\
\text { Tiempo: } 15 \text { minutos } \\
\text { El facilitador expone la } \\
\text { conferencia sobre educación } \\
\text { ambiental (problemática } \\
\text { ambiental, educación ambiental, } \\
\text { su historia, enfoques } \\
\text { metodológicos y estrategias). } \\
\text { El facilitador realiza preguntas } \\
\text { sobre lo expuesto. } \\
\text { Tiempo: } 1 \text { hora. } \\
\text { El facilitador desarrolla una } \\
\text { estrategia didáctica que consiste } \\
\text { en integrarse en equipos para } \\
\text { realizar un sociodrama sobre } \\
\text { algún problema ambiental dentro } \\
\text { o fuera de la escuela. El } \\
\text { sociodrama es actuado y grabado } \\
\text { en video (con el teléfono celular). } \\
\text { Se envían los videos al } \\
\text { facilitador, se presentan en la } \\
\text { clase y se hacen comentarios. } \\
\text { Tiempo: } 2 \text { horas. } \\
\text { instrumento de evaluación sobre }\end{array}$ & $\begin{array}{l}\text { Investiga } \\
\mathrm{r} \text { en } \\
\text { fuentes } \\
\text { confiable } \\
\mathrm{s} \text { de } \\
\text { internet } \\
\text { qué son } \\
\text { los } \\
\text { manglare } \\
\text { s. }\end{array}$ & $\begin{array}{l}\text { Comprensi } \\
\text { ón, } \\
\text { análisis e } \\
\text { identificac } \\
\text { ión de } \\
\text { estrategias } \\
\text { de } \\
\text { educación } \\
\text { ambiental } \\
\text { para } \\
\text { intervenir } \\
\text { ante una } \\
\text { problemáti } \\
\text { ca } \\
\text { ambiental. }\end{array}$ & $\begin{array}{l}\text { Preguntas sobre } \\
\text { las } \\
\text { problemáticas } \\
\text { ambientales. } \\
\text { Preguntas sobre } \\
\text { la educación } \\
\text { ambiental (su } \\
\text { historia, } \\
\text { enfoques } \\
\text { estrategias). } \\
\\
\text { Práctica } \\
\text { sociodrama del } \\
\text { sobre } \\
\text { problema } \\
\text { ambiental. } \\
\\
\text { Evaluación final } \\
\text { de la sesión 1. }\end{array}$ & $50 \%$ & $\begin{array}{l}\text { Bibliog } \\
\text { rafía } \\
\text { sobre } \\
\text { educaci } \\
\text { ón } \\
\text { ambient } \\
\text { al } \\
\text { recome } \\
\text { ndada } \\
\text { para } \\
\text { esta } \\
\text { sesión. }\end{array}$ \\
\hline
\end{tabular}




\begin{tabular}{|c|c|c|c|c|c|c|}
\hline & $\begin{array}{l}\text { aprendizajes adquiridos durante } \\
\text { la sesión. } \\
\text { Tiempo: } 30 \text { minutos }\end{array}$ & & & & & \\
\hline & Tiempo: 4 horas & $\begin{array}{c}\text { Tiempo: } \\
2 \text { horas }\end{array}$ & & & & \\
\hline $\begin{array}{l}\text { Sesión } 2 \\
\text { (13 de junio } \\
\text { de 2019) } \\
\text { Educación } \\
\text { ambiental } \\
\text { para la } \\
\text { conservació } \\
\text { n de los } \\
\text { manglares. }\end{array}$ & $\begin{array}{l}\text { Con respecto a la tarea de la } \\
\text { sesión anterior, referida a los } \\
\text { manglares, se solicita a los } \\
\text { estudiantes su investigación } \\
\text { acerca de los mangles. } \\
\text { Tiempo: } 30 \text { minutos. } \\
\text { El facilitador aplica un } \\
\text { instrumento diagnóstico a los } \\
\text { estudiantes para determinar } \\
\text { cuáles son sus conocimientos } \\
\text { sobre el tema de manglares. } \\
\text { Tiempo: } 1 \text { hora la } \\
\text { El facilitador expone la } \\
\text { conferencia Educación } \\
\text { ambiental para la conservación } \\
\text { de los mangles en zonas costeras } \\
\text { (qué son, tipos, dónde crecen, } \\
\text { beneficios e importancia en el } \\
\text { medio y la comunidad, etc.). } \\
\text { Realiza preguntas, se hacen } \\
\text { comentarios, etc. } \\
\text { Tiempo: } 1 \text { hora. } \\
\text { Aplicación de técnica: De } \\
\text { manera grupal, plantean } \\
\text { compromisos para cuidar y } \\
\text { preservar el medio ambiente, la } \\
\text { biodiversidad y principalmente } \\
\text { los ecosistemas de manglar. } \\
\text { Tiempo: } 1 \text { hora. } \\
\text { El facilitador aplica por segunda } \\
\text { vez el instrumento diagnóstico } \\
\text { que tuvo como finalidad conocer } \\
\text { los conocimientos que tenían los } \\
\text { estudiantes sobre los manglares } \\
\text { adquiridos en el curso. }\end{array}$ & $\begin{array}{l}\text { Impleme } \\
\text { ntar lo } \\
\text { aprendid } \\
\text { o en la } \\
\text { vida } \\
\text { cotidiana } \\
\text {. }\end{array}$ & $\begin{array}{l}\text { Analizar la } \\
\text { importanci } \\
\text { a de la } \\
\text { educación } \\
\text { ambiental } \\
\text { para } \\
\text { conservar } \\
\text { los } \\
\text { manglares } \\
\text { por lo que } \\
\text { representa } \\
\text { n. }\end{array}$ & 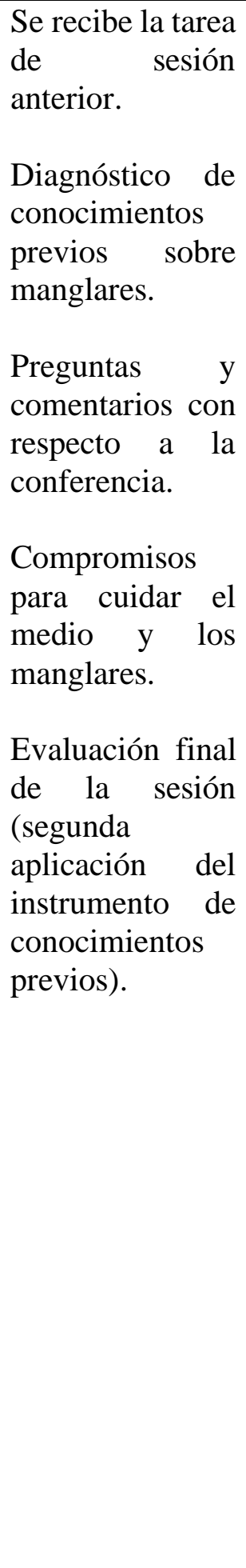 & $50 \%$ & $\begin{array}{l}\text { Bibliog } \\
\text { rafía de } \\
\text { educaci } \\
\text { ón } \\
\text { ambient } \\
\text { al y } \\
\text { mangla } \\
\text { res para } \\
\text { esta } \\
\text { sesión. }\end{array}$ \\
\hline
\end{tabular}




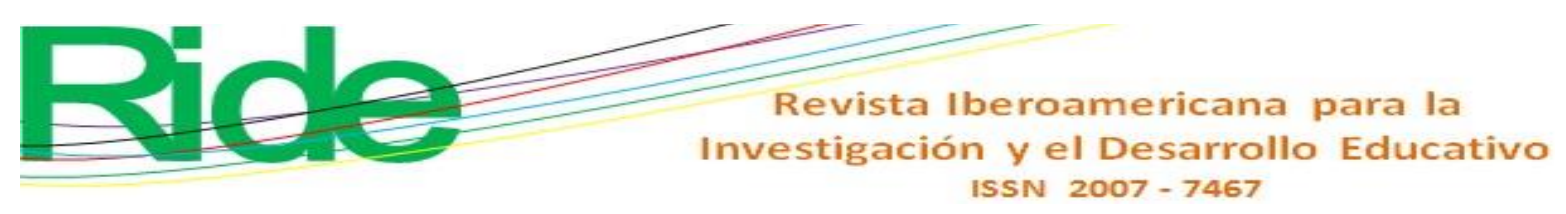

Fase c: Aplicación y evaluación del curso-taller

El curso-taller se denominó Educación ambiental para la sustentabilidad y para la conservación de manglares y fue desarrollado en dos sesiones: la primera el 28 de mayo de 2019, y la segunda el 13 de junio de 2019. Asistieron 70 estudiantes.

En la primera sesión se diagnosticaron los conocimientos previos de los participantes en cuanto a educación ambiental. Las respuestas que proporcionó el grupo fueron registradas por el docente facilitador y agrupadas según los criterios de la tabla 3:

Tabla 3. Evaluación grupal de conocimientos previos sobre la problemática ambiental y la educación ambiental

\begin{tabular}{|c|c|c|c|c|}
\hline Criterios & $\begin{array}{c}\text { Excelent } \\
\text { e }\end{array}$ & $\begin{array}{c}\text { Satisfactori } \\
\text { o }\end{array}$ & $\begin{array}{c}\text { Poco } \\
\text { satisfacto } \\
\text { rio }\end{array}$ & $\begin{array}{c}\text { Totalmente } \\
\text { insatisfactori } \\
0\end{array}$ \\
\hline $\begin{array}{l}\text { Reconoce las problemáticas } \\
\text { ambientales. } \\
\text { Comprende el concepto } \\
\text { educación ambiental }\end{array}$ & & & $\begin{array}{l}\mathrm{X} \\
\mathrm{X}\end{array}$ & \\
\hline $\begin{array}{l}\text { Identifica las problemáticas } \\
\text { ambientales globales y } \\
\text { locales. } \\
\text { Relaciona la educación } \\
\text { ambiental solo con naturaleza }\end{array}$ & $X$ & & $\mathrm{X}$ & \\
\hline $\begin{array}{l}\text { Relaciona la problemática } \\
\text { ambiental como un elemento } \\
\text { que afecta al medio e impide } \\
\text { la sustentabilidad. } \\
\text { Relaciona la educación } \\
\text { ambiental con una } \\
\text { herramienta para lograr la } \\
\text { sustentabilidad }\end{array}$ & & & & X \\
\hline Resultado final: Las resp & $\begin{aligned} & \text { stas al } \\
& \text { sup }\end{aligned}$ & $\begin{array}{l}\text { as (cono } \\
\text { les. }\end{array}$ & ntos pr & fueron \\
\hline
\end{tabular}

Fuente: Elaboración propia 


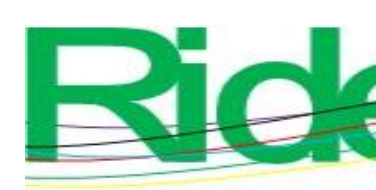

\section{Revista Iberoamericana para la Investigación y el Desarrollo Educativo ISSN 2007 - 7467}

Continuando con la primera sesión, en el horario de 10:30 a 11:30 los facilitadores expusieron en Power Point la conferencia sobre la educación ambiental (problemática ambiental, su historia, enfoques metodológicos y estrategias), la cual se desarrolló en tres fases (al finalizar cada una se realizaban preguntas y comentarios). En la primera parte de la conferencia se ofreció una reflexión general acerca de la educación ambiental: antecedentes, principales enfoques y estrategias que se pueden implementar para actuar responsablemente. Asimismo, se dio a conocer que el tema de la educación ambiental ha sido uno de los más tratados en foros internacionales desde 1970 hasta la actualidad.

Luego se realizó una lluvia de ideas a partir de preguntas como las siguientes: ¿qué se puede decir en torno a la educación ambiental y su importancia?, ¿qué enfoque de trabajo plantea dicho concepto y qué estrategias y acciones podrían implementarse para tener un medio ambiente sano?, ¿cuáles serían los problemas ambientales globales y locales y cómo estos impactan en el desarrollo económico y social?, ¿qué tan importante resulta tener un medio ambiente sano tanto natural como urbano?

Estas interrogantes sirvieron para concienciar a los participantes sobre los propósitos de la educación ambiental y sobre cómo este concepto resulta determinante no solamente para cuidar la naturaleza, sino también para contribuir al desarrollo sustentable. Respecto al cuidado de un medio ambiente sano, comentaron que deben conservarse los espacios limpios y evitar contaminarlos, para lo cual son indispensables las estrategias que ofrece la educación ambiental.

En la segunda parte de la conferencia se trataron las causas de las problemáticas ambientales y la identificación de las estrategias que se podían desarrollar; también se comentaron algunos problemas que tienen su origen en actividades antropogénicas y se presentaron algunos métodos, acciones o estrategias que pueden ser implementadas para reducir o minimizar los efectos que el hombre produce sobre el medio. Al finalizar esta parte de la conferencia se planteó a los asistentes la siguiente interrogante: ¿cuáles son las principales causas de la contaminación? Las respuestas hicieron énfasis en los plásticos, la sobrepoblación, el consumismo, los incendios y la deforestación por la tala de árboles. Algunas de las dudas que surgieron entre los alumnos fueron estas: ¿cómo se pueden frenar las actividades que realiza el hombre sobre el medio?, ¿qué podemos hacer como individuos ante las grandes corporaciones?, ¿cómo se puede reducir el consumismo si nos bombardean con productos?, ¿cómo hacer que los políticos cambien y hagan cumplir las leyes en materia ambiental?, entre otras. Algunas propuestas que surgieron de estas reflexiones fueron las 


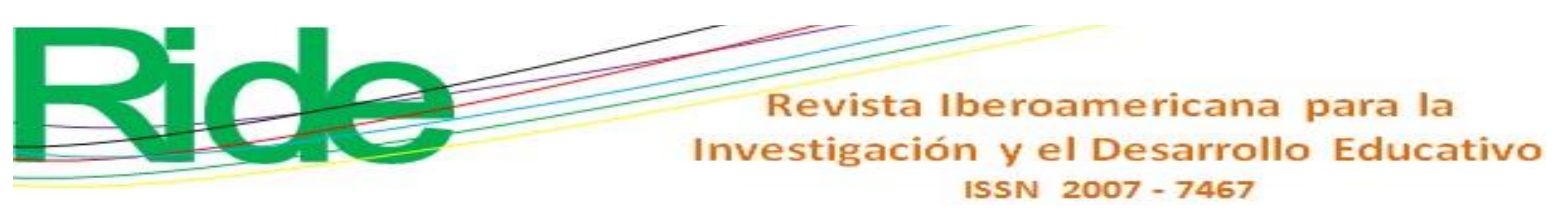

siguientes: implementar la reforestación cuando se talan los árboles y promover por parte del Gobierno políticas que permitan regular la contaminación de las fábricas, los autos, etc.

La tercera parte de la conferencia se enfocó en una introducción al tema residuos sólidos urbanos (RSU), su manejo regular y su manejo deseado. Para esto, se analizaron las etapas de un programa de educación ambiental (diagnóstico, definición de estrategias, planeación y evaluación). Asimismo, se hizo un análisis de las estrategias, así como de la estructura de un programa de educación ambiental y de sus principales tendencias y modelos en el sistema escolar. Al finalizar, se formularon las siguientes interrogantes: ¿qué son los RSU y cómo se pueden manipular (disposición e importancia del reciclado) ?, ¿qué son los programas de educación ambiental y cuál es su finalidad?

Las respuestas permitieron identificar que los estudiantes no cuentan con una cultura adecuada sobre el manejo de los RSU, aunque subrayaron que la basura se debía dejar en lugares apropiados. Además, apuntaron que se podrían clasificar los residuos antes de llevarlos al depósito.

En el horario de 11:30 a 13:30 — con fundamento en la información de la conferencia-, se promovió una actividad grupal para realizar un sociodrama sobre algún problema ambiental detectado dentro o fuera de la escuela, para lo cual también debían proponer alguna solución. Los estudiantes actuaron en el sociodrama, lo grabaron con sus teléfonos celulares y lo enviaron al facilitador. En esta actividad solo se pudieron formar tres grupos de cinco personas porque los demás estudiantes prefirieron observar la participación de sus compañeros. Los temas elegidos fueron contaminación del aire, generación de residuos sólidos urbanos y uso inadecuado del agua. Posteriormente, los equipos salieron del aula para localizar la problemática, dramatizarla y grabarla. Terminada la actividad, regresaron al aula y enviaron al facilitador los videos para que fueran proyectados en el aula.

En general, se observó la creatividad por parte de los participantes, pues cada sociodrama resultó diferente: dos de los equipos representaron el trabajo a través de reportajes, mientras que el tema del agua fue tratado como una situación del día a día en la escuela (carencias del agua, desperdicio, etc.). El argumento fue totalmente coherente con la temática desarrollada en la sesión y se aplicaron adecuadamente los principios de las estrategias. Durante la presentación de los videos, los estudiantes reflexionaron sobre los problemas detectados y realizaron comentarios y preguntas. 


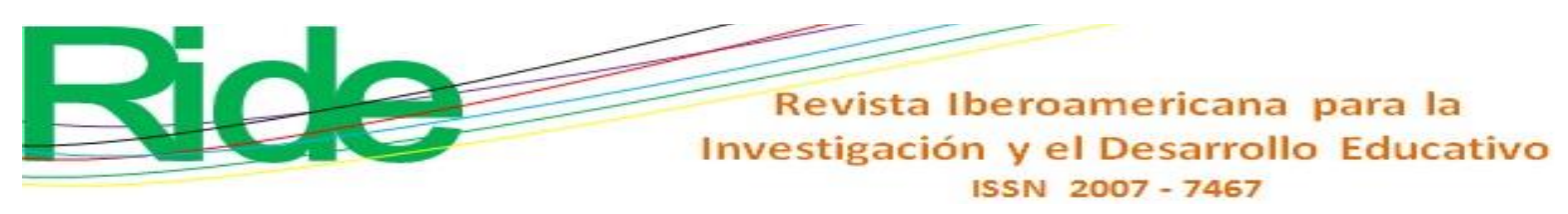

Esta actividad se evaluó a través de una rúbrica que se apoyó en los siguientes criterios: trabajo colaborativo, argumento, dramatización, creatividad y presentación. Cada criterio se evaluó con excelente (4), bien (3), regular (2) y mal (1). De manera general, se puede decir que la actividad cumplió con su propósito.

En el horario de 13:30 a 14:00, los alumnos contestaron un instrumento de evaluación de manera grupal sobre los aprendizajes adquiridos. Se realizaron algunas preguntas sobre las temáticas que se desarrollaron en esta sesión para recabar una información general de los aprendizajes y competencias adquiridas. Los resultados se describen a continuación en la tabla 4: 


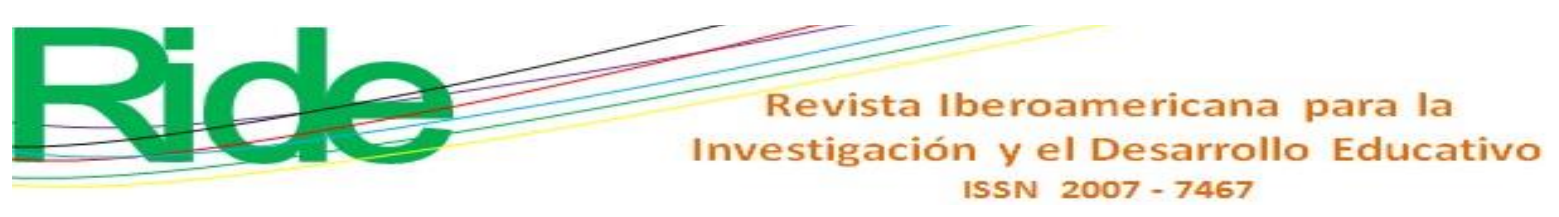

Tabla 4. Evaluación grupal de conocimientos adquiridos en la primera sesión del programa

\begin{tabular}{|c|c|c|c|c|c|}
\hline \multicolumn{2}{|l|}{ Criterios } & \multirow{2}{*}{$\begin{array}{c}\text { Excelent } \\
\text { e } \\
\\
\mathrm{X}\end{array}$} & \multirow{2}{*}{$\begin{array}{c}\text { Satisfactori } \\
\text { o }\end{array}$} & \multirow{2}{*}{$\begin{array}{c}\text { Poco } \\
\text { satisfacto } \\
\text { rio }\end{array}$} & \multirow{2}{*}{$\begin{array}{l}\text { Insatisfactor } \\
\text { io }\end{array}$} \\
\hline & $\begin{array}{l}\text { Reconoce las problemáticas } \\
\text { ambientales. }\end{array}$ & & & & \\
\hline & $\begin{array}{l}\text { Comprende el concepto } \\
\text { educación ambiental. }\end{array}$ & $\mathrm{X}$ & & & \\
\hline & $\begin{array}{l}\text { Identifica las problemáticas } \\
\text { ambientales globales y locales. }\end{array}$ & $X$ & & & \\
\hline & $\begin{array}{l}\text { Relaciona la educación } \\
\text { ambiental solo con naturaleza. }\end{array}$ & & & $X$ & \\
\hline & $\begin{array}{l}\text { Relaciona la problemática } \\
\text { ambiental como un elemento } \\
\text { que afecta al medio e impide la } \\
\text { sustentabilidad. }\end{array}$ & $X$ & & & \\
\hline & $\begin{array}{l}\text { Relaciona la educación } \\
\text { ambiental con una herramienta } \\
\text { para lograr la sustentabilidad. }\end{array}$ & $\mathrm{X}$ & & & \\
\hline & $\begin{array}{l}\text { Promueve actitudes y aptitudes } \\
\text { responsables ante el medio. }\end{array}$ & $\mathrm{X}$ & & & \\
\hline & $\begin{array}{l}\text { Pondré en marcha estrategias } \\
\text { para cuidar el medio ambiente. }\end{array}$ & $X$ & & & \\
\hline & \begin{tabular}{|lrr} 
Es importante & implementar \\
programas de & educación \\
ambiental & & \\
\end{tabular} & $\mathrm{X}$ & & & \\
\hline & $\begin{array}{l}\text { Conoce ahora el propósito de la } \\
\text { educación ambiental. }\end{array}$ & $\mathrm{X}$ & & & \\
\hline & $\begin{array}{l}\text { Resultado final: Las respuestas e } \\
\text { ahora se comprende que los estu } \\
\text { sobre la temática que trató la sesi }\end{array}$ & $\begin{array}{l}\text { cuanto a } \\
\text { iantes log } \\
\text { n. }\end{array}$ & $\begin{array}{l}\text { s conocimien } \\
\text { aron adquirir }\end{array}$ & $\begin{array}{l}\text { s previos fi } \\
\text { prendizajes }\end{array}$ & $\begin{array}{l}\text { ron superadas; } \\
\text { competencias }\end{array}$ \\
\hline
\end{tabular}

Fuente: Elaboración propia 


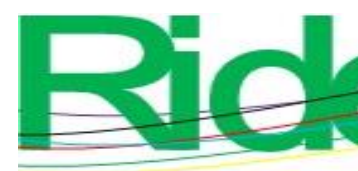

\section{Revista Iberoamericana para la Investigación y el Desarrollo Educativo \\ ISSN $2007-7467$}

Al finalizar la primera sesión se asignó una actividad para que fuera presentada en la siguiente. El trabajo solicitado fue indagar en fuentes confiables de Internet la definición de los manglares.

\section{Resultados de la segunda sesión}

La segunda sesión se desarrolló el 13 de junio de 2019 con una asistencia de 70 estudiantes. El nombre de esta segunda sesión fue Educación ambiental para la conservación de los manglares, la cual duró cuatro horas (de 10:00 a 14:00). En el horario de 10:00 a 10:30, se solicitó a los estudiantes la asignación sobre los manglares:

Tabla 5. Evaluación de conocimientos previos sobre los manglares

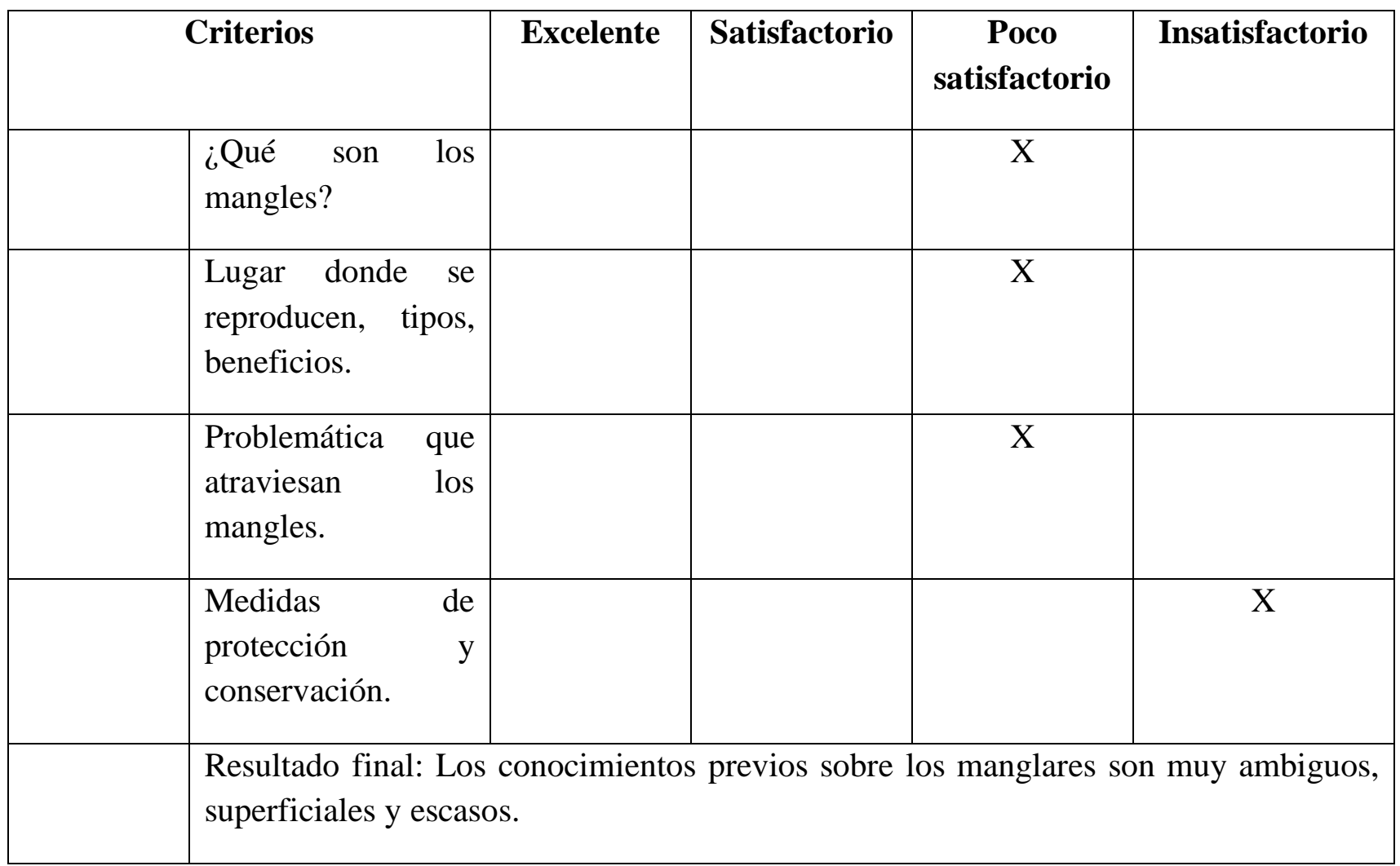

Fuente: Elaboración propia

En el horario de 10:30 a 11:30, los facilitadores aplicaron una entrevista abierta a los estudiantes para identificar los conocimientos que poseían sobre los manglares. Las preguntas formuladas aparecen en la tabla 6. Las respuestas se analizaron cualitativamente de manera grupal y se organizaron en indicadores de medición (excelente, satisfactorio, poco satisfactorio e insatisfactorio): 


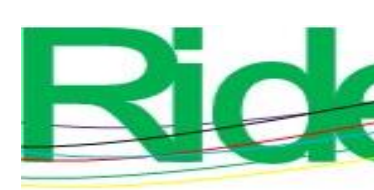

Revista Iberoamericana para la
Investigación y el Desarrollo Educativo
ISSN $2007-7467$

Resultado final: Las respuestas de los estudiantes sobre las preguntas planteadas fueron ambiguas; sin embargo, se aprecia que en las interrogantes relacionadas con el taller de la sesión 1, las respuestas son más completas.

Fuente: Elaboración propia

En el horario de 11:30 a 12:30, los facilitadores expusieron la conferencia Educación ambiental para la conservación de los mangles en zonas costeras (qué son, tipos, dónde crecen, beneficios e importancia en el medio y la comunidad, etc.). Al terminar, se formularon preguntas y se solicitaron comentarios sobre los temas tratados. En síntesis, los participantes opinaron que el tema de la educación ambiental resulta vital para conservar los ecosistemas de manglar, en especial en el estado de Guerrero.

Luego, entre las 12:30 y las 13:30, se solicitó a los alumnos que escribieran sus compromisos para el cuidado de dichos ecosistemas. Las propuestas presentadas se enfocaron en la preservación del manglar debido a su importancia para el medio y para otros aspectos sociales.

En el horario de 13:30 a 14:00, el facilitador aplicó por segunda vez el instrumento (relacionado con las interrogantes de la tabla 5) para comparar los conocimientos adquiridos por los estudiantes luego del curso-taller. De manera general, se puede afirmar que todos los participantes tomaron más conciencia sobre el cuidado y la preservación del manglar.

\section{Discusión}

\section{El plan de estudio de la institución}

En primer lugar, se pude indicar que la inclusión de la dimensión ambiental y la sustentabilidad en el plan de estudio cursado por los participantes es escasa, pues las materias vistas no se vinculan con los temas referidos. De hecho, no se aplica una metodología transversal para desarrollar las dimensiones ambiente, sociedad y economía, a pesar de que en el modelo educativo de la Universidad Autónoma de Guerrero vigente (2013) se establecen como principios la responsabilidad social, el desarrollo sustentable y la formación.

Para promover los temas concernientes al medio ambiente es necesario que la institución y los profesores pertenecientes promuevan cursos, talleres o programas de educación ambiental no formales para que estudiantes desarrollen competencias y adquieran aprendizajes en esta materia. Igualmente, se puede integrar en el currículo formal la dimensión ambiental como tema transversal para que los alumnos consoliden sus competencias ambientales. 


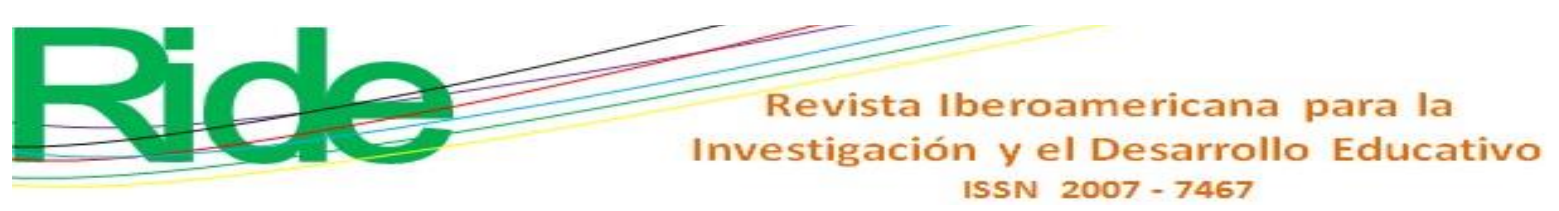

conocimientos sobre la especie y sus hábitats, y mostraron cambios actitudinales y participativos notables.

Por otra parte, Linares et al. (2004) efectuaron un proyecto para intentar concienciar a los niños de la Escuela Primaria Federal Juan Escutia, Mapastepec, Chiapas (México) sobre la importancia ecológica y económica del cuidado y la preservación de los recursos del manglar en beneficio de las comunidades. Las actividades propuestas en dicho trabajo se apoyaron en exposiciones con videos, juegos y otras actividades escolares. Las conclusiones de este trabajo demuestran que las iniciativas sobre educación ambiental brindan resultados que benefician a los recursos naturales y, en consecuencia, a las propias personas. Así mismo, Yanez y Álvarez (2019b) afirman que distintos países deben incorporar el principio de transversalidad curricular en la enseñanza de la Educación Ambiental para el desarrollo sostenible a través de sus sistemas educativos. Lo estipulado anteriormente, obedece a que en los currículos de todos los niveles educativos debe darse importancia a la Educación para el Desarrollo Sostenible por la importancia que representa.

\section{Conclusiones}

La presente investigación cumplió sus propósitos, es decir, se atendieron los principios del modelo educativo de la UAGro, pues se tomó el tema de la sustentabilidad como un principio orientador para atender la problemática ambiental. De hecho, al detectar que existía una escasa dimensión ambiental en el plan de estudio donde se realizó este trabajo, se contribuyó con un programa de educación ambiental no formal para tratar el tema de la conservación del manglar. De esta forma se procuró que los estudiantes adquirieran aprendizajes y competencias sustentables no solo para conservar los manglares, sino también para enfrentar la crisis ambiental, específicamente en el estado de Guerrero.

Para desarrollar este tipo de programas de educación ambiental, por supuesto, primero se debe elegir la metodología didáctica y pedagógica idónea para luego llevar a cabo un diseño que se ajuste al contexto donde se piensa aplicar.

Finalmente, se puede apuntar que los resultados del diagnóstico desarrollado mostraron la necesidad de incluir la dimensión ambiental en el currículo formal, así como los métodos didácticos no formales para proteger los recursos naturales. La universidad, por tanto, debe incorporar en sus planes de estudio la educación ambiental como tema transversal no formal, de manera que los estudiantes promuevan competencias ambientales para enfrentar con propuestas de 


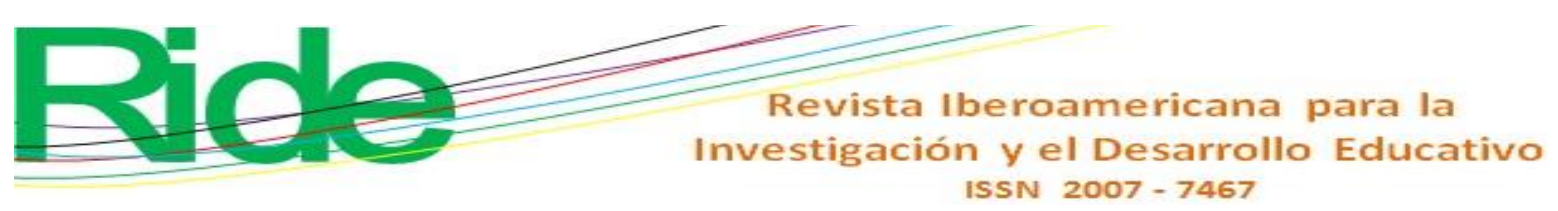

solución las problemáticas ambientales actuales. En definitiva, no se pueden descuidar los beneficios que ofrecen los manglares para el ambiente y para lo social.

\section{Referencias}

Aguirre, L. (2018). Plan para la conservación del manglar en la comunidad del Carrizal Coyuca de Benítez, Guerrero (tesis de maestría). Universidad Autónoma de Guerrero, Acapulco, Guerrero, México.

Aparicio, J., Rodríguez, C. y Beltrán, J. (2014). Metodología para la transversalidad del eje medio ambiente. Revista Iberoamericana de Ciencias Sociales y Humanidades, 10(30), 53-68.

Calixto, R. (2015). Educación ambiental para la sustentabilidad en la educación secundaria. Revista Actualidades Investigativas en Educación, 15(3), 1-21.

Calixto, R. (2018). Una experiencia en educación ambiental con estudiantes universitarios. Journal of Sustainability Education, 18, 1-15.

Carrasco, M. y Vásquez, E. (2016). La educación ambiental: un saber necesario en la formación universitaria. Primer Congreso Nacional de Educación Ambiental para la Sustentabilidad. Eje EAS en las instituciones educativas. ANEA.

Colmenares, A. y Piñero, M. (2008) La investigación acción. Una herramienta metodológica heurística para la comprensión y transformación de realidades y prácticas socio-educativas. Revista Laurus, 14(27), 96-114.

Cuevas, L., Rocha, V., Casco, R. y Martínez, M. (2011). Punto de encuentro entre constructivismo y competencias. AAPAUMAN. Academia de Ciencia y Cultura, 5-8.

Díaz, J. (2011). Una revisión sobre los manglares: características, problemáticas y su marco jurídico. Importancia de los manglares, daño de los efectos antropogénicos y su marco: caso sistema lagunar de Topolobampo. Rev. Ra Ximhai, 7(3), 355-369.

Estenssoro, F. (2018). Escasez de recursos naturales y crisis ambiental como amenazas estratégicas a la seguridad de los Estados Unidos. Las implicaciones para América Latina en el siglo XXI. Revista Estudios Avanzados, (28), 170-186.

Forero, M. y Mahecha A. M. (2006). Una estrategia de conservación en San Andrés Isla: proyectos escolares y valores en la educación ambiental. Revista Gestión y Ambiente, 9(3), 1-14.

González, M. (1996). Principales tendencias y modelos de la educación ambiental en el sistema escolar. Revista Iberoamericana de Educación, 11, 13-74. Doi: 10.35362/rie1101157 


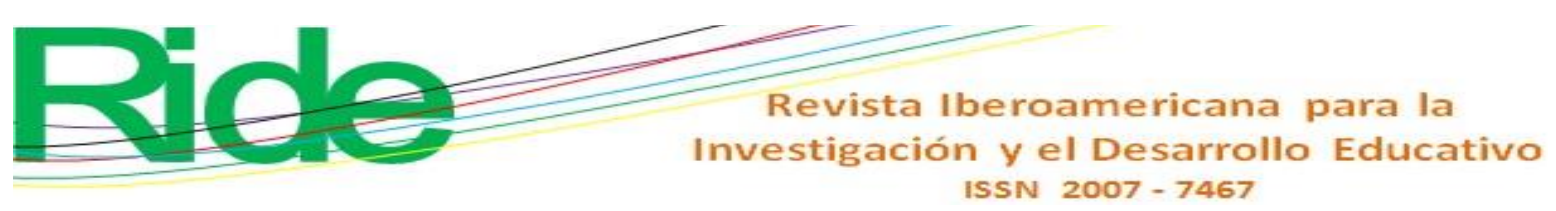

González, P. (18 de mayo de 2018). Manglar: ¿qué es y qué tipos hay? Ok Diario Ciencia. Recuperado de https://okdiario.com/ciencia/manglar-que-que-tipos-hay-2285444

Greenpeace (2009). México. Sin control la pérdida de manglares en México. Recuperado de https://www.greenpeace.org/archive-mexico/es/Noticias/2009/Julio/manglar/

Heredero, L. (15 de abril de 2011). Manglares: un escudo natural contra el cambio climático. NEWS Mundo. Recuperado de https://www.bbc.com/mundo/noticias/2011/04/110415_verde_manglares_contra_cambio_ climatico_lh

Linares, R., Tovilla, C. y De la Presa, J. (2004). Educación ambiental: una alternativa para la conservación del manglar. Revista Madera y Bosques, 10(especial 2), 105-114.

López, J. y Ezcurra, E. (2002). Los manglares de México: una revisión. Revista Madera y Bosques, $8(1), 27-51$.

Martínez, M. (2006). La investigación cualitativa (síntesis conceptual). Revista IIPSE, 9(1), 123 146.

Martínez Castillo, R. (2010). La importancia de la educación ambiental ante la problemática actual. Revista electrónica Educare, 14(1), 97-111.

Mera, V. (1999). Género, manglar y subsistencia. Recuperado de https://digitalrepository.unm.edu/cgi/viewcontent.cgi?article=1508\&context=abya_yala

Molano, A. y Herrera, F. (2014). La formación ambiental en la educación superior: una revisión necesaria. Revista Luna Azul, (39), 186-206.

Moreno-Casasola, P. e Infante, D. M. (2016). Conociendo los manglares, las selvas inundables y los humedales herbáceos. Recuperado de http://www.itto.int/files/itto_project_db_input/3000/Technical/Conociendo\%20los\%20ma nglares $\% 20 \mathrm{y} \% 20$ selvas\%20inundables.pdf.

Nieto, L. y Buendía, O. (2008). Guía para el análisis de contexto de un proyecto de un proyecto de educación ambiental. México: (UASLP) Universidad Autónoma de San Luis Potosí.

Nieto-Caraveo, L. M. (2001). Modalidades de la educación ambiental: diversidad y desafíos. Brasil: Rima Editorial.

Novo, M. (1996). La educación ambiental formal y no formal: dos sistemas complementarios. Revista Iberoamericana de Educación, (11), 75-102. 


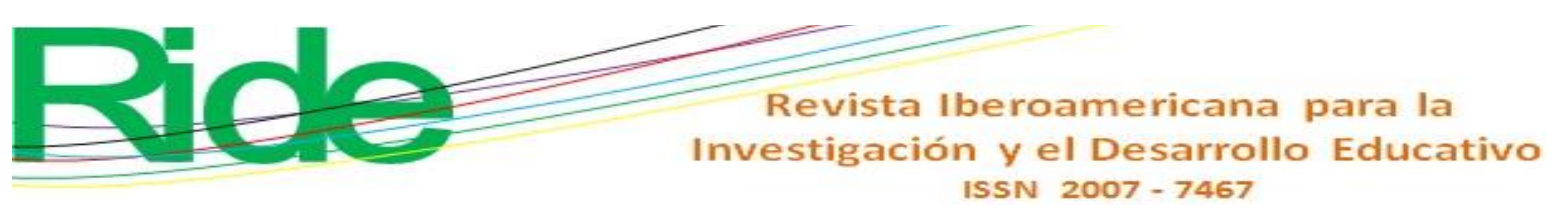

Olguín, E., Hernández, M. y Sánchez, G. (2007). Contaminación de manglares por hidrocarburos y estrategias de biorremediación, fitorremediación y restauración. Rev. Int. Contaminación Ambiental, 23(3), 139-154.

Osses, S., Sánchez, I. e Ibáñez, F. (2006). Investigación cualitativa en educación. Hacia la generación de teoría a través del proceso analítico. Estudios Pedagógicos, 32(1), 119-133. Doi: 10.4067/S0718-07052006000100007

Oxford Dictionaries (2019). Language matters. Retrieved from http://www.oxforddictionaries.com/es/definicion/espanol/diseno?q=dise\%C3\%B1o

Plascencia, R, Castañón, A. y Raz-Guzmán, A. (2011). La biodiversidad en México: su conservación y las colecciones biológicas. Revista Ciencias, (101), 36-43.

Ramírez, O. (2015). Identificación de problemáticas ambientales en Colombia a partir de la percepción social a partir de estudiantes universitarios localizados en diferentes zonas del país. Rev. Int. de Contaminación Ambiental, 31(3), 293-310.

Rodríguez, M., Villeda, E., Vásquez-Lule, A., Bejarano, M., Cruz, M., Olguín, M. Villena, S. y Flores, R. (2018). Métodos para la caracterización de los manglares mexicanos, un enfoque espacial multiescala. Recuperado de https://www.biodiversidad.gob.mx>metodos>caracterizacion_manglares.

Ruiz, C. (s. f.). Diseño de proyectos de educación ambiental. Recuperado de http://www.juntadeandalucia.es/medioambiente/educacion_ambiental/disenoProyectos.pd $\mathrm{f}$

Secretaría de Medio Ambiente y Recursos Naturales [Semarnat] (2016). Los manglares mexicanos. Recuperado de https://www.gob.mx/semarnat/articulos/manglares-mexicanos

Serrano, J. y Pons, R. (2011). El constructivismo hoy: enfoques constructivistas en educación. Revista Electrónica de Investigación Educativa, 13(1), 1-27.

Severiche-Sierra, C., Gómez-Bustamante, E. y Jaimes-Morales, J. (2016). La educación ambiental como base cultural y estrategia para el desarrollo sostenible. Revista Telos, 18(2), 266-281.

Tobón. T., Pimienta, P. y García, J. (2010). Secuencias didácticas: aprendizaje y evaluación de competencias. México: Ed. Pearson Educación.

Universidad Autónoma de Guerrero [UAGro] (2013). Modelo educativo: hacia una educación de calidad con inclusión social. UAGro. Recuperado de http://ingenieria.uagro.mx/inicio/files/normativa/Modelo_Educativo_de_la_UAGro.pdf 


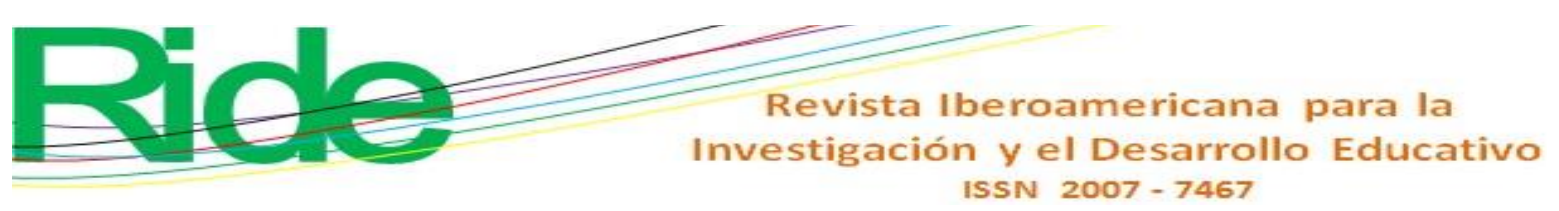

Uribe, J. y Urrego, L. (2009). Gestión ambiental de los ecosistemas de manglar. Aproximación al caso colombiano. Revista Gestión y Ambiente, 12(2), 57-71.

Valderrama, L., Rodríguez, M., Troche, C., Velázquez, S., Villeda, E., Alcántara, Vázquez, B. Cruz, L. y Ressl, R. (2017). Manglares de México: actualización y exploración de los datos del sistema de monitoreo 1970/1980-2015. Recuperado de https://agua.org.mx/biblioteca/manglares-mexico-actualizacion-exploracion-los-datos-delsistema-monitoreo-19701980-2015/

Yanes, L. G. y Álvarez., D. M. B. (2019). Transversalidad de la educación ambiental para el desarrollo sostenible. Revista Universidad y Sociedad, 11(5).

Yépez, G. (2018). La educación ambiental como freno a la degradación de la naturaleza. El caso del manglar estuario río esmeraldas. Areté. Revista Digital del Doctorado en Educación de la Universidad Central de Venezuela, 4(8), 87-102. 


\begin{tabular}{|c|c|}
\hline Rol de Contribución & Autor (es) \\
\hline Conceptualización & $\begin{array}{l}\text { Adriana Miranda Esteban “igual» Ramón Bedolla Solano } \\
\text { «principal» }\end{array}$ \\
\hline Metodología & $\begin{array}{l}\text { Ramón Bedolla Solano «principal» Adriana Miranda Esteban } \\
\text { «igual» Juan José Bedolla Solano «igual» }\end{array}$ \\
\hline Software & $\begin{array}{l}\text { Adriana Miranda Esteban «principal» Ramón Bedolla Solano } \\
\text { «iguall» Juan José Bedolla Solano «igual» }\end{array}$ \\
\hline Validación & $\begin{array}{l}\text { Ramón Bedolla Solano «principal» Adriana Miranda Esteban } \\
\text { «igual» Juan José Bedolla Solano «igual» }\end{array}$ \\
\hline Análisis Formal & $\begin{array}{l}\text { Ramón Bedolla Solano «principal» Adriana Miranda Esteban } \\
\text { «igual» }\end{array}$ \\
\hline Investigación & $\begin{array}{l}\text { Ramón Bedolla Solano «igual» Adriana Miranda Esteban } \\
\text { "igual» Oscar Sánchez Adame «igual» Juan José Bedolla } \\
\text { Solano «igual» }\end{array}$ \\
\hline Recursos & $\begin{array}{l}\begin{array}{l}\text { Ramón Bedolla Solano «principal» Adriana Miranda Esteban } \\
\text { «igual» }\end{array}\end{array}$ \\
\hline Curación de datos & $\begin{array}{l}\text { Ramón Bedolla Solano «principal» Adriana Miranda Esteban } \\
\text { «igual» }\end{array}$ \\
\hline $\begin{array}{l}\text { Escritura - Preparación del } \\
\text { borrador original }\end{array}$ & $\begin{array}{l}\text { Ramón Bedolla Solano«principal» Adriana Miranda Esteban } \\
\text { «igual» }\end{array}$ \\
\hline $\begin{array}{l}\text { Escritura - Revisión y } \\
\text { edición }\end{array}$ & $\begin{array}{l}\text { Ramón Bedolla Solano «principal» Adriana Miranda Esteban } \\
\text { «igual» Oscar Sánchez Adame «igual» Juan José Bedolla } \\
\text { Solano «igual» }\end{array}$ \\
\hline Visualización & $\begin{array}{l}\text { Ramón Bedolla Solano «principal» Adriana Miranda Esteban } \\
\text { «igual» Oscar Sánchez Adame «igual» Juan José Bedolla } \\
\text { Solano «igual» }\end{array}$ \\
\hline Supervisión & $\begin{array}{l}\text { Ramón Bedolla Solano «principal» Adriana Miranda Esteban } \\
\text { «igual» Oscar Sánchez Adame «igual» Juan José Bedolla } \\
\text { Solano «igual» }\end{array}$ \\
\hline $\begin{array}{l}\text { Administración de } \\
\text { Proyectos }\end{array}$ & $\begin{array}{l}\text { Ramón Bedolla Solano «principal» Adriana Miranda Esteban } \\
\text { "igual» }\end{array}$ \\
\hline Adquisición de fondos & $\begin{array}{l}\text { Ramón Bedolla Solano «principal» Adriana Miranda Esteban } \\
\text { "igual» }\end{array}$ \\
\hline
\end{tabular}

